$12 / 8.939811$

UCRL-ID-112943

\title{
Numerical Simulation of Turbulent Mixing and Combustion Near the Inlet of a Burner
}

\author{
Lawrence D. Cloutman
}

February 1993

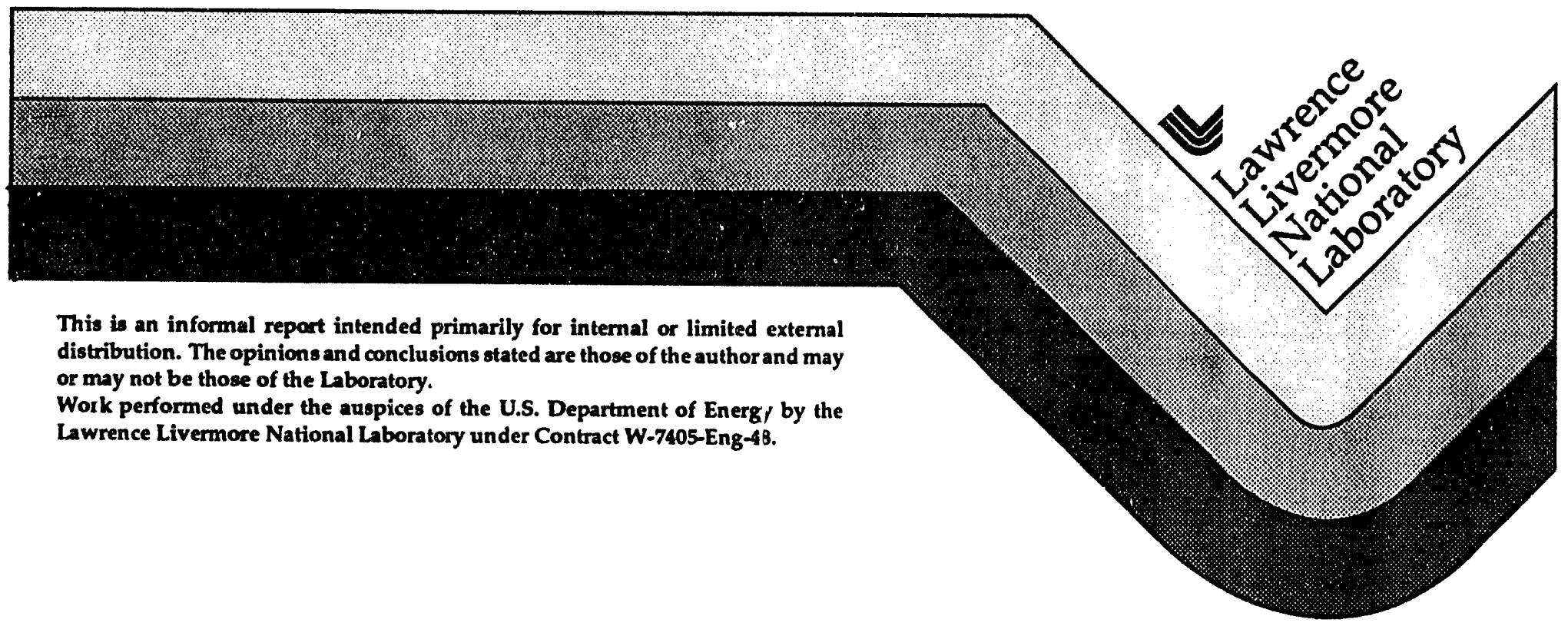




\section{DISCLAIMER}

This document was prepared as an account of work sponsored by an agency of the United States Government. Neither the United States Government wor the University of Californila nor any of their employees, makes any warranty, express or implied, or assumes any legal liablitity or responsibility for the accuracy, completeness, or usefulness of any information, apparatus, product, or process disclosed, or represents that its use would not infringe privately owned rights. Reference herein to any specific commercial products, process, or service by trade name, trademark, manufacturer, or otherwise, does not necessarily constitute or imply its endorsement, recommendation, or favoring by the United States Government or the University of Callfornia. The views and opinions of authors expressed herein do not necessarily state or reflect those of the United States Government or the University of Calfiornia, and shall not be used for advertising or product endorsement purposes.

This report has beea reproduced directly from the best available copy.

Available to DOE and DOE contractors from the Oritice of Scientific and Technical Information

P.O. Box 62, Oak Ridge, TN 37831

Prices avallable from (615) 576-8401, FTS 626-8401

A vailable to the public from the National Technical Information Service

US. Department of Commerce 5285 Port Royal Rd. Springtield, VA 22161 


\author{
NUMERICAL SIMULATION OF TURBULENT MIXING \\ AND COMBUSTION NEAR THE INLET OF A BURNER \\ Lawrence D. Cloutman \\ Computational Physics Division, L-298 \\ Lawrence Livermore National Laboratory \\ Livermore, California 94551
}

\begin{abstract}
The COYOTE computer program was used to simulate the flow field and turbulent mixing near the fuel and air inlets in a simplified burner that was proposed ior experimental study at the Combustion Laboratory at the University of California at Irvine. Four cases are presented, with and without chemical reactions, with two different outflow boundary conditions, and with two different swirl numbers. These preliminary results demonstrate the ability of COYOTE to simulate burners, and they illustrate some limitations and requirements of such modeling.
\end{abstract}




\section{INTRODUCTION}

The COYOTE numerical fluid dynamics program [1] was designed to simulate reacting flows in two-dimensional Cartesian and axisymmetric geometries. The current version of the program has a variety of turbulence models, including the LUVD11 turbulence model [2] and the $k-\epsilon$ model [3-5]. This program was applied to simulations of a simplified burner that was proposed for experimental investigation at the University of California at Irvine for the California Institute for Energy Efficiency (CIEE). The long-range goal of this study is to identify parameters that affect the production of $\mathrm{NO}_{\mathbf{x}}$ and to discover methods of reducing emissions while maintaining or improving efficiency. The present calculations represent a baseline study performed as the first step in reaching this goal.

The burner is axisymmetric, and the geometry of the nozzle used to inject air and natural gas into the combustion chamber is shown in Fig. 1. The vertical and horizontal lines outline the computational zones. Diagonal lines show the locations of solid obstacles. The grid in this figure covers a region $5.08 \mathrm{~cm}$ square, and the quarl is chamfered at a $45^{\circ}$ angle. Methane is injected through the angled channel at the lower left, and swirling air is injected through the vertical channel next to the fuel injector. Figure 2 shows the full grid used for the three near-injector simulations. This grid occupies a region $12.0 \mathrm{~cm}$ square. The channel at the bottom center of the grid is for secondary air, which is not used in these calculations. The experimental nozzle and flame zone are confined inside a combustion chamber, which is a hexagonal prism approximated by a cylinder $30.48 \mathrm{~cm}$ in radius and $93.98 \mathrm{~cm}$ tall above the entrance plane of the fuel nozzle. The chamber is $91.44 \mathrm{~cm}$ tall above the top of the quarl, and it is topped by a roof with a slope of $45^{\circ}$ that necks down to fit a $15.24 \mathrm{~cm}$ diameter chimney. The present computational mesh is much smaller than this enclosure, so we use an adiabatic free-slip boundary along the right boundary and a fixed pressure subsonic outflow boundary along the top of the grid. All calculations place the bottom of the computational grid at the exit plane of the fuel nozzle. The flow conditions correspond to a heating rate of $29.3 \mathrm{~kW}\left(1.0 \times 10^{5} \mathrm{Btu} / \mathrm{hr}\right)$. 
COYOTE is based on the full transient Navier-Stokes equations, and "steady-state" solutions are found by assuming an arbitrary initial flow and allowing the transient to decay. While this approach is less efficient computationally than a direct steady state approach, it has several advantages. First, it does not make the ad hoc assumption that the final flow field is truly steady. That is, it allows the final solution to contain quasi-periodic features such as flame flickering. If the final flow is truly steady, then that type of solution will evolve naturally. Second, it automatically performs a flame stability study. If, for example, the flame cannot be sustained, it should be extinguished in the calculation (at least to the extent that the gas physics included in the calculation is an accurate representation of the physical system). Third, it allows easy incorporation of complex gas physics, such as detailed chemical kinetics. The main disadvantage is that the computational expense is higher than for a direct steady-state solver. However, in today's world of relatively abundant and inexpensive computational power, we can afford to trade a certain amount of computational expense (in both algorithmic efficiency and the inclusion of physical detail) for an improvement in accuracy and reliability of the solutions. We address this issue further at the end of the next section.

Section II describes the simulations of the flow in and near the fuel injection nozzle for four different conditions. Conclusions are presented in Section III.

\section{FLOW NEAR THE FUEL INJECTION NOZZLE}

COYOTE is based on the full Navier-Stokes equations for a mixture of compressible gases. The equations, turbulence model, and numerical algorithms have been described in detail elsewhere $[1,2]$ and will not be repeated here. Species diffusion is modeled by Fick's law and the heat flux is modeled by Fourier's law plus enthalphy diffusion.

The thermal equation of state is the sum of partial pressures for each species treated as an ideal gas. The species internal energies are functions of temperature taken from the JANAF tables 
[6-8]. The mixture viscosity is assumed to be given by

$$
\mu=1.457 \times 10^{-5} T^{3 / 2} /(110+T),
$$

where $T$ is the absolute temperature. The thermal conductivity is calculated from the viscosity using a constant Prandtl number with a value of 0.7 . The species diffusivities are assumed to be equal and are calculated from the viscosity and a constant Schmidt number, also 0.7.

The chemical reaction network consists of a single global reaction for methane oxidation to $\mathrm{H}_{2} \mathrm{O}$ and $\mathrm{CO}_{2}$, the extended Zel'dovich mechanism for thermal NO production, and six molecular equilibrium reactions for the dissnciation of $\mathrm{H}_{2} \mathrm{O}, \mathrm{CO}_{2}, \mathrm{H}_{2}, \mathrm{O}_{2}, \mathrm{~N}_{2}$, and $\mathrm{OH}$. The reactions are listed in Table 1. The fuel oxidation reaction rate was inspired by the work of Westbrook and Dryer [9], and we used

$$
k_{\mathrm{ov}}=9.5 \times 10^{14}\left[\mathrm{CH}_{4}\right]^{0.25}\left[\mathrm{O}_{2}\right]^{1.5} \exp (-24358 / T)
$$

As discussed in the introduction, the geometry of the experiment is shown in Figs. 1 and 2. The experimental combustion chamber and nozzle are axisymmetric, which allows us to make this preliminary study with two-dimensional calculations. We limit the mesh in these first calculations to a 90 by 90 nonuniform mesh covering a region $12.0 \mathrm{~cm}$ square in the $r-z$ plane. The bottom of the mesh is along the exit plane of the fuel-air nozzle. The zones are $0.079375 \mathrm{~cm}$ square at the lower left corner, growing slowly to $\delta x=0.4144425 \mathrm{~cm}$ and $\delta y=0.4266154 \mathrm{~cm}$ at the upper right corner. The top of the grid is an outflow boundary with a specified pressure of $1.0 \times 10^{6}$ dynes $/ \mathrm{cm}^{2}$. The annular natural gas jet has inner and outer radii of 0.238125 and $0.47625 \mathrm{~cm}$ respectively (radial zones 5 through 7 ), and the annular swirl air jet has inner and outer radii of 0.635 and $1.27 \mathrm{~cm}$ respectively (radial zones 10 through 17 ). Secondary air was not used in these calculations, although a channel was left for it in the obstacles.

The swirl number is defined by, for example [10-12],

$$
S w=\frac{\int_{R_{0}}^{R_{1}} \rho v w r^{2} d r}{R_{1} \int_{R_{0}}^{R_{1}} \rho v^{2} r d r}
$$


where $R_{0}$ and $R_{1}$ are the inner and outer radii of the annulus. In this study, we assume that $\rho$, $v$, and $\omega=w / r$ are constant over each opening. With these approximations, the swirl number reduces to

$$
\mathrm{Sw}=\frac{\omega\left(R_{1}^{2}+R_{0}^{2}\right)}{2 v R_{1}}
$$

Calculations were performed with $\mathrm{Sw}=0$ and 0.316 .

We assume that the inflowing gases are at a temperature of $300 \mathrm{~K}$ and a pressure of $1.0 \times 10^{6}$ dynes $/ \mathrm{cm}^{2}$. The inflow velocities are $1.4129687 \times 10^{3} \mathrm{~cm} / \mathrm{s}$ for both components of the natural gas velocity and $2.260198 \times 10^{3}$ for the vertical component of the air velocity. These correspond to volumetric flow rates of $1.6 \mathrm{scfm}$ for the fuel and $18.2 \mathrm{scfm}$ for the air. The air was assumed to have a constant angular velocity of $\omega=900 \mathrm{~s}^{-1}$ for the two swirling flow cases with $\mathrm{Sw}=0.316$. The inflow densities are $6.41482 \times 10^{-4} \mathrm{~g} / \mathrm{cm}^{3}$ for the natural gas and $1.16181 \times 10^{-3} \mathrm{~g} / \mathrm{cm}^{3}$ for the air. The natural gas was modeled as pure methane. The air was assumed to be a mixture of 4 species with mass fractions of $0.23154 \mathrm{O}_{2}, 0.755159 \mathrm{~N}_{2}, 0.0133 \mathrm{CO}_{2}$, and $1.29109 \times 10^{-6} \mathrm{H}_{2} \mathrm{O}$. The flow rates are summarized in Table 2. The carbon dioxide mass fraction was artificially enhanced by about 0.01 to represent approximately the mass fraction of argon, which has a similar molecular weight. The trace of water in the inflowing air was omitted from the initial stationary ambient air in the combustion chamber to separate the initial air from the injected air and to help determine the degree of mixing of the various gas streams. That is, in the nonreactive case, the amounts of water and methane in a zone are an indicator of the degree of local mixing of the two inflowing streams, and zones with neither methane nor water have not mixed at all with the inflowing gases. The gravitational acceleration is assumed to be $980 \mathrm{~cm} / \mathrm{s}^{2}$. Gravity is often omitted in combustion simulations, but in these slow flows with large density variations and long integration times, it is prudent to include it, especially since there is no computational penalty for doing so. Indeed, Ellzey and Oran [13] found that their simulations of the flow field in a jet diffusion flame were quite sensitive to gravity.

The first solution we consider is the swirling cold flow case. This case illustrates two difficulties 
in modeling burners. The first difficulty occurs when using an outflow boundary with subsonic flows. A subsonic outflow boundary may be implemented by setting the pressure outside the mesh and assuming all other quantities have a zero normal gradient on the boundary. A similar approach using a nonreflecting boundary condition has been proposed $[14,15]$. Both have been used successfully, and both suffer from a problem that arises when the outflow becomes an inflow. The solution becomes unstable in the sense that we do not know the values of the flow variables coming back into the grid, so the solution determined by the flow-reversal of the outflow algorithm can slowly drift into nonphysical regimes. The second difficulty is the elliptical nature of the problem, which is manifested by boundary conditions having their influence felt a long distance from the boundary.

The next four figures show the swirling cold flow solutions for two different outflow conditions. In the first one, inflow is prevented by setting the axial velocity to zero if it tries to go negative. In the second one, the axial velocity is allowed to be either positive or negative. Figure 3 shows the velocity vectors for the two cases, with vectors being plotted at every other zone. The top panel shows the vectors with inflow prevented. The solution is attempting to create inflow along the conterline, but the dominant flow feature is the fuel-air stream flowing upward and radially outward (due to the swirl). There is a small vortex near the right wall, but this is not dynamically important and may in fact be transient. There is also a small recirculation zone just above the fuel nozzle, but it too is not dynamically important. When we allow inflow at the top, the flow becomes dominated by the inflow along the axis, which was slowly increasing its speed when the calculation was terminated at this point.

Figure 4 shows the streamline plots for the two nonreactive cases. The streamline plots artificially emphasize the recirculation at the right, which has a low velocity but a si'gnificant mass flow rate due to the radial factors of the cylindrical geometry. Figure $4 \mathrm{~A}$ shows the fuel-air stream that is rising and expanding radially. In the inflow case, the recirculation domirates everything to the point that the streamlines created at the fuel-air nozzle do not even show up on Fig. 4B (which has 9 equally spaced contours). 
Figures 5 and 6 show the swirl velocity contours and the contours of fuel mass fraction. Again we see large differences between the two outflow boundary conditions. Figure 5B, which allows inflow at the top, shows that the strong nonswirling downflow of air along the axis quickly mixes with the injected methane and swirling air, resulting in dramatically different contour plots. This is due to the assumption that inflowing material is pure air, an arbitrary assumption that reflects our ignorance of what is actually going on above the top boundary. The conclusion from this pair of solutions and some simulations of the full enclosure (which will be reported in a later report) is that predicting the correct flow in the neighborhood of the nozzle requires doing the calculation on a much larger grid, perhaps even requiring inclusion of the eniire enclosure.

Figure 7 shows the velocity vector plot for the reactive flow case with the same flow conditions as the cold flow cases. Although this calculation was performed with the same conditions, the flow pattern is quite different than in either Fig. 3A or 3B. The flow inside the quarl is more like that in Fig. 3B, but that is the extent of the similarities. The flame sheet lies along the main stream of fluid running from the nozzle upward and to the right in the lower $2 / 3$ of the mesh, and then bending back to the left in the upper $1 / 3$ of the mesh. There are two recirculation zones along the axis, one inside the quarl and a larger one up higher. These recirculations are not pulling fluid in through the upper boundary and have saturated in amplitude. They may, however, try to merge if the problem were run further out in time. To the extent that these small-mesh runs are realistic, they suggest that the procedure of running a cold flow and then freezing that flow pattern while postprocessing the chemistry is unreliable. The two phenomena interact too strongly to be decoupled that way.

Figure 8 shows the stream function for the reactive flow. The main flow feature is the stream of burning gases that comes in through the nozzles and out the upper boundary. As also shown by the velocity vectors, the streamlines are different than in either of the cold flow solutions.

Figure 9 shows the swirl velocity for the reactive flow. The swirl distribution is intermediate between the two panels in Fig. 5. Figure 5A shows significant swirl all the way from the nozzle to the upper boundary, whereas Fig. $5 \mathrm{~B}$ has the swirl confined the quarl face. Figure 9 shows a 
concentration of swirl along the quarl face plus a region of significant swirl along the axis at the top of the large recirculation region inside the flame sheet. The swirl concentration on the quarl face is very similar to that shown in Fig. $5 B$, and it is likely that the upper swirl concentration is due to the spinup of weakly swirling fluid as it flows toward the axis in the upper recirculation zone. However, it is premature to assign a firm physical interpretation to these swirl plots due to the extreme sensitivity to the outflow boundary and to the fact that the swirl distributions reach steady state very slowly. These examples may not be very well relaxed as the solutions were terminated when it became apparent that a larger volume around the nozzle needs to be included in the calculations.

Figure 10 shows the turbulence kinetic energy density (TKE) for the reactive swirling flow. The inflowing air is assumed to have a TKE of $10^{3} \mathrm{~cm}^{2} / \mathrm{s}$ and the fuel has a TKE of $10^{-2} \mathrm{~cm}^{2} / \mathrm{s}$. Additional turbulence is produced by shear at the edges of the nozzles and decays very quickly above the nozzles. The peak turbulence intensity is only slightly higher in the reactive case than in the cold flow cases, and the strongest turbulence is confined to the inside of the quarl in both cases. Above the quarl, the TKE is less than 10 percent of the peak value. The turbulence contributes an eddy viscosity comparable to the molecular viscosity only in the first few centimeters above the top of the quarl. Since the highest turbulence levels are confined to such a small region, we may need even better resolution to get a good representation of the turbulent mixing.

Figure 11 shows the isotherms for the reactive swirling flow. They clearly show the flame sheet, with its sinuous shape. The flame extends down into the quarl, almost to the exit plane of the nozzle. The recirculation zone between the axis and the flame sheet is filled with high temperature reaction products, which is where NO is produced by the thermal mechanism. It is not clear where the luminous flame would appear along the contours since at some axial location the fuel has been consumed and the isotherms simply separate cold air and relatively inert hot reaction products. The contours of density show a striking resemblance to the isotherms and consequently are not shown.

The lump of warm fluid at the upper right corner of Fig. 11 is an artifact of the outflow 
boundary. It is very difficult to produce a numerical subsonic outflow boundary condition that does not reflect unwanted signals back into the mesh, and this lump is half of a vortex ring propagating to the right along a portion of the outflow boundary that acts as a rigid boundary. Flow wants to come into the mesh at that location, and we prevent inflows in this example. However, if the correct solution for the problem at hand is a true steady state without inflow along the top, our boundary condition will produce the correct answer. It can have difficulty with transients, which is our present situation, where we are approaching a presumed steady state through a transient. Rudy and Strikwerda [15] discuss this problem in some detail and suggest that we may be able to reduce our computational effort simply by upgrading the numerical inflow and outflow boundary conditions. Our inflow boundary condition is the type (ii) with specified density of Rudy and Strikwerda.

Figures 12 through 15 show mass fractions of four important species. Figure 12 shows the mass fraction contours of methane for the reactive swirling flow. The outermost contour (labeled B) is 9 percent methane by mass, so the equivalence ratio is approximately 2 along that contour. The region of fuel too rich to burn is less than $2 \mathrm{~cm}$ tall. The turbulent mixing of fuel and air occurs very close to the injector, similar to the situation shown in Fig. 6B.

Figure 13 shows the mass fraction of molecular oxygen. To the right of the main contours is cold, essentially unreacted air with a mass fraction as large as $\mathbf{0 . 2 3 2}$. To the left, the oxygen has been depleted to a mass fraction as low as $4.2 \times 10^{-5}$. The contours in the far bottom left corner are due to the displacement of air by unreacted fuel, but otherwise oxygen depletion is an indication of reacted fluid. Figure 14 shows mass fraction contours of water vapor, which is produced by the combustion process. Both Figs. 13 and 14 show that the recirculation zone above the flame is flled with reaction products.

Figure 15 shows the NO mass fraction contours for the reactive fluw case. The model produces NO only by the thermal mechanism, so the rule of thumb is that the highest NO concentrations tend to be in the fluid elements that have been the hottest for the longest time. The recirculation zone will keep residence times up for at least part of the fluid, and NO continues to be produced 
as the fluid works its way upward. The grid appears to be too short to contain the region where the updraft finally cools to the point where the NO production freezes out.

The final solution is a reactive flow case using the same parameters as the other solutions except for a swirl number of zero. The nature of the solution is quite different than in the swirling case. The flow above the nozzle is essentially axial until it hits the reaction zone, which wants to stand off several centimeters. There is an insignificant recirculation region extending approximately $1 \mathrm{~cm}$ above the fuel nozzle. The flame had a strong tendency to die out in some early attempts to start the calculation, but it is very robust in the swirling case. This behavior is evidence of the role of swirl in stabilizing flames. The results shown in Figs. 16-19 are still in a transient phase. Figure 16 shows the velocity vectors, and Fig. 17 shows the stream function. Without swirl, the axial air jet dominates the angled fuel jet, resulting in a nearly axial flow with a vortex ring at the tip of unburned jet. Figures 16 and 17 show this vortex ring quite clearly in the upper left quadrant of the mesh. Figure 18 shows the isotherms, and we see the reaction zone is located near the axis and the upper boundary. Figure 19 shows the mass fraction of methane, and we see the flame stands off the nozzle at least partly because the fuel and air must travel several centimeters axially before they are sufficiently mixed to support combustion. Compared with Fig. 12, the fuel Inass fraction shows much less mixing with the air in the immediate neighborhood of the nozzle in spite of the fact that the peak TKE is nearly the same in both cases. This calculation was carried further out in time, and the reaction zone left the mesh. An accurate simulation of this case will require a grid with more space above the burner.

The calculations reported here were performed on an IBM RS/6000 workstation. The short time steps imposed by the chemistry $(<2 \mu \mathrm{s})$ and the long integration times required to get "steady" solutions ( $>0.1 \mathrm{~s}$ ) require the calculation of many time steps, which requires a few tens of hours for each problem. The long running times are a result of the desire to use adequate resolution of the fuel-air nozzle and the philosophy of using a time-marching approach based on the full Navier-Stokes equations. What is gained in this approach in return for the increased computational expense is minimization of modeling uncertainties by minimizing ad hoc assumptions built into the 
model such as happens with a direct steady-state approach. In particular, this approach provides the correct interaction between fluid dynamics and chemistry, automatic stability tests of "steady" solutions, and the inclusion of acoustic modes and oscillatory, nearly periodic solutions if present.

\section{CONCLUSIONS}

The COYOTE hydrodynamics program has been used to simulate flows in a simplified burner. The primary objectives of this study are 1) to demonstrate the feasibility of using this program and turbulence model to simulate burners; 2) to determine procedures and model features that will be required to produce accurate and reliable solutions; 3 ) to begin pushing forward with the development of the next generation of models with advanced capabilities, such as the inclusion of a large eddy simulation (LES) turbulence model and improved chemical kinetics; and 4) to draw conclusions about the physics of burners within the limits allowed by the limited reliability of the solutions presented in this report. The absence of experimental data on this burner makes it difficult to assess the accuracy of these calculations, but they appear to be reasonable. However, as is usual with a first attempt at solving a problem, we found several ways in which the simulations will have to be improved before we can consider the model to be reliable. A numerical study of a different burner that includes the improvements discussed in the previous section and for which there is detailed experimental data has been performed and will be reported in a separate report.

The most important result of these preliminary numerical solutions is the identification of a number of areas that are critical to the accurate simulation of burners:

1) In the swirling reactive case, the on-axis recirculation zone just above the nozzle is much larger, much stronger, and more complex than in the cold flow case. This implies that the chemistry-flow field interaction is very strong and must be done self consistently. In particular, we would not get reliable results by doing a cold flow calculation to get the flow pattern and then doing chemistry on this frozen flow field.

2) A larger mesh is required, and it is desirable to include the entire enclosure around the 
burner. Not only are there uncertainties introduced by the outflow boundary treatment, but the influence of all boundary conditions is felt a large distance into the mesh. This is a manifestation of the elliptic nature of the problem. We now employ an outflow boundary that does not reflect signals back into the mesh as a means of speeding up the relaxation process. Inflow at an outflow boundary should be prevented as it can produce a slowly drifting nonphysical component into the solution.

3) High turbulence levels and chemical mixing occur very close to the injector. Consequently, good resolution is needed in that part of the mesh, and numerical experiments to test the adequacy of the present grid are needed. Furthermore, the low turbulence levels far from the nozzle suggest that we should provide a more detailed calculation of the molecular transport coefficients.

4) These burner simulations are spatially and temporally "stiff." We need submillimeter resolution near the nozzle, but the enclosure is a meter tall. The chemistry time step is less than $2 \mu \mathrm{s}$, the hydrodynamical stability limit is several times larger, and the requirea integration time approaches a second. Consequently, we need both a large number of zones and a large number of computational cycles. There is no obvious way around this difficulty without sacrificing physical detail.

Additional calculations including a limited zoning study, inclusion of the entire enclosure, and a wall function model of boundary layers are in progress. A chemistry model including prompt NO is under development, as is improved numerical diagnostic software. These will be documented in future reports.

\section{ACKNOWLEDGMENTS}

I thank Charles Westbrook, Scott Samuelsen, Bill Sowa, and Matt Miyasato for helpful conversations in defining the problem. I also thank Lila Chase, Bill Pitz, and Jay McGowan for their aid in making COYOTE a functional tool on a variety of computing platforms. Finally, I thank Tom McAbee for communicating his experience with the turbulence model. This work was sup- 
ported by the California Institute for Energy Efficiency and Southern California Gas Company. This work was performed under the auspices of the U.S. Department of Energy and the Lawrence Livermore National Laboratory under contract number W-7405-ENG-48.

\section{REFERENCES}

1. L. D. Cloutman, "COYOTE: A Computer Program for 2-D Reactive Flow Simulations," Lawrence Livermore National Laboratory Report No. UCRL-ID-103611, 1990.

2. L. D. Cloutman, "The LUVD11 Large Eddy Simulation Model," Lawrence Livermore National Laboratory Report No. UCRI,-ID-107128, 1991.

3. B. E. Launder and D. B. Spalding, Mathematical Models of Turbulence (Academic Press, London, 1972).

4. B. E. Launder and D. B. Spalding, "The numerical computation of turbulent flows," Comp. Meth. App. Mech. Eng. 3, 269 (1974).

5. W. P. Jones, "Models for turbulent flows with variable density and combustion," ir. Prediction Methods for Turbulent Flows, edited by W. Kollmann (Hemisphere, Washington, 1980), D. 379.

6. D. R. Stull and H. Prophet, "JANAF thermochemical tables, 2nd ed.," U. S. Department of Commerce/National Bureau of Standards Report No. NSRDS-NBS 37, 1971.

7. M. W. Chase, J. L. Curnutt, A. T. Hu, H. Prophet, A. N. Syverud, and L. C. Walker, "JANAF thermochemical table, 1974 supplement," J. Phys. Chem. Ref. Data 3, 311 (1974).

8. M. W. Chase, Jr., C. A. Davies, J. R. Downey, Jr., D. J. Frurip, M. A. McDonald, and A. N. Syverud, "JANAF thermochemical tables, third edition, parts I and II," J. Phys. Chem. Ref. Data 14 Suppl. No. 1, (1985).

9. C. K. Westbrook and F. L. Dryer, "Simplified reaction mechanisms for the oxidation of hydrocarbon fuels in flames," Comb. Sci. Tech. 27, 31 (1981).

10. E. E. Khalil, Modelling of Furnaces and Combustors (Abacus Press, Tunbridge Wells, UK, 1982), p. 218.

11. A. K. Gupta and D. G. Lilley, Flowfield Modeling and Diagnostics (Adacus Press, Tunbridge Wells, UK, 1985).

12. A. K. Gupta, D. G. Lilley, and N. Syred, Swirl Flows (Abacus Press, Tunbridge Wells, UK, 1984).

13. J. L. Ellzey and E. S. Oran, "Effects of heat release and gravity on an unsteady diffusion flame," in the Proceedings of the 23rd Symposium (International) on Combustion (The Combustion Institute, Pittsburgh, 1990), pp. 1635-1640.

14. D. H. Rudy and J. C. Strikwerda, "A Nonreflecting Outflow Boundary Condition for Subsonic Navier-Stokes Calculations," J. Comput. Phys. 36, 55 (1980). 
15. D. H. Rudy and J. C. Strikwerda, "Boundary Conditions for Subsonic Compressible NavierStokes Calculations," Comput. \& Fluids 9, 327 (1981).

Table 1. Chemical Reaction Network

\begin{tabular}{ll}
\hline \multicolumn{1}{c}{ Kinetic } & Equilibium \\
\hline $\mathrm{CH}_{4}+2 \mathrm{O}_{2} \rightarrow \mathrm{CO}_{2}+2 \mathrm{H}_{2} \mathrm{O}$ & $\mathrm{N}_{2} \rightleftharpoons 2 \mathrm{~N}$ \\
$\mathrm{O}+\mathrm{N}_{2} \rightleftharpoons \mathrm{NO}+\mathrm{N}$ & $\mathrm{H}_{2} \rightleftharpoons 2 \mathrm{II}$ \\
$\mathrm{N}+\mathrm{O}_{2} \rightleftharpoons \mathrm{NO}+\mathrm{O}$ & $\mathrm{O}_{2} \rightleftharpoons 2 \mathrm{O}$ \\
$\mathrm{OH}+\mathrm{N} \rightleftharpoons \mathrm{NO}+\mathrm{H}$ & $\mathrm{O}_{2}+\mathrm{H}_{2} \rightleftharpoons 2 \mathrm{OH}$ \\
& $\mathrm{O}_{2}+2 \mathrm{H}_{2} \mathrm{O} \rightleftharpoons 4 \mathrm{OH}$ \\
& $\mathrm{O}_{2}+2 \mathrm{CO} \rightleftharpoons 2 \mathrm{CO}_{2}$ \\
\hline
\end{tabular}

Table 2. Mass Inflow Rates

\begin{tabular}{lll}
\hline \hline Species & Flow Rate $(\mathrm{g} / \mathrm{s})$ & Stoichiometry \\
\hline Total & 10.463697 & \\
Fuel & $4.843933 \times 10^{-1}$ & \\
Swirl Air & 9.979304 & \\
Sec. Air & 0. & \\
& & \\
$\mathrm{CH}_{4}$ & $4.843933 \times 10^{-1}$ & \\
$\mathrm{O}_{2}$ & 2.310608 & \\
$\mathrm{~N}_{2}$ & 7.535961 & \\
$\mathrm{CO}_{2}$ & $1.327247 \times 10^{-1}$ & \\
$\mathrm{H}_{2} \mathrm{O}$ & $1.288418 \times 10^{-5}$ & \\
& & \\
$\mathrm{C}$ & $3.994926 \times 10^{-1}$ & $\frac{3}{4} \dot{m}\left(\mathrm{CH}_{4}\right)+\frac{3}{11} \dot{m}\left(\mathrm{CO}_{2}\right)+\frac{3}{7} \dot{m}(\mathrm{CO})$ \\
$\mathrm{H}$ & $1.210998 \times 10^{-1}$ & $\frac{1}{4} \dot{m}\left(\mathrm{CH}_{4}\right)+\frac{1}{9} \dot{m}\left(\mathrm{H}_{2} \mathrm{O}\right)+\dot{m}(\mathrm{H})+\dot{m}\left(\mathrm{H}_{2}\right)+\frac{1}{17} \dot{m}(\mathrm{OH})$ \\
$\mathrm{N}$ & 7.535961 & $\dot{m}\left(\mathrm{~N}_{2}\right)+\dot{m}(\mathrm{~N})+\frac{7}{15} \dot{m}(\mathrm{NO})$ \\
$\mathrm{O}$ & 2.407147 & $\dot{m}\left(\mathrm{O}_{2}\right)+\dot{m}(\mathrm{O})+\frac{8}{11} \dot{m}(\mathrm{CO})+\frac{8}{9} \dot{m}\left(\mathrm{H}_{2} \mathrm{O}\right)+\frac{16}{17} \dot{m}(\mathrm{OH})$ \\
& & $+\frac{4}{7} \dot{m}(\mathrm{CO})+\frac{8}{15} \dot{m}(\mathrm{NO})$ \\
\hline
\end{tabular}




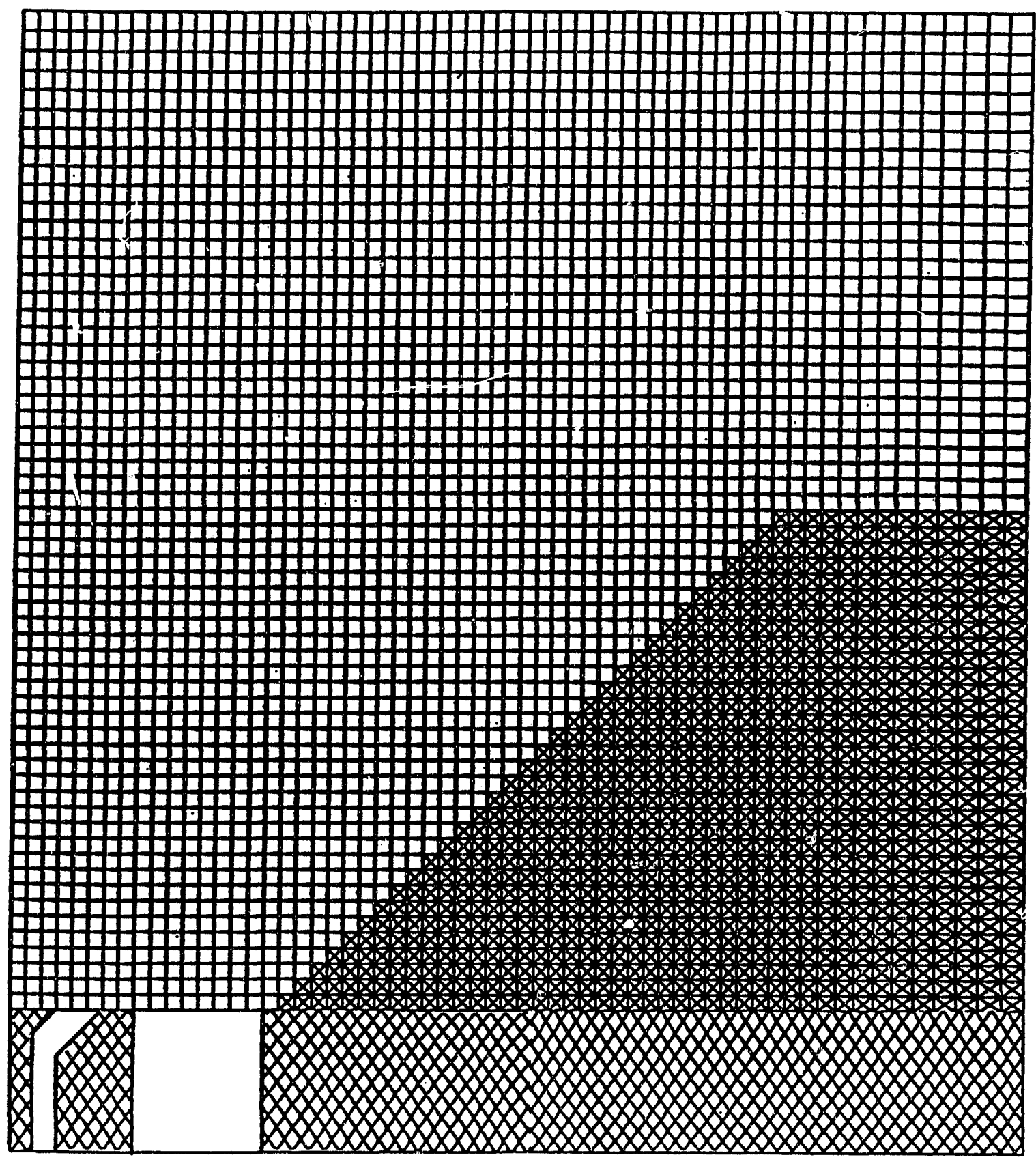

Fig. 1. C :oss section of the nozzle used to inject air and fuel into the combustion chamber. The vertical ind horizontal lines outline the computational zones. Diagonal lines show the locations of solid obstacles. Methane is injected through the angled channel at the lower left, and swirling air is injected through the vertical channel next to the fuel injector. The quarl is chamfered at a $45^{\circ}$ angle. This grid occupies a region $5.08 \mathrm{~cm}$ by $5.08 \mathrm{~cm}$. 


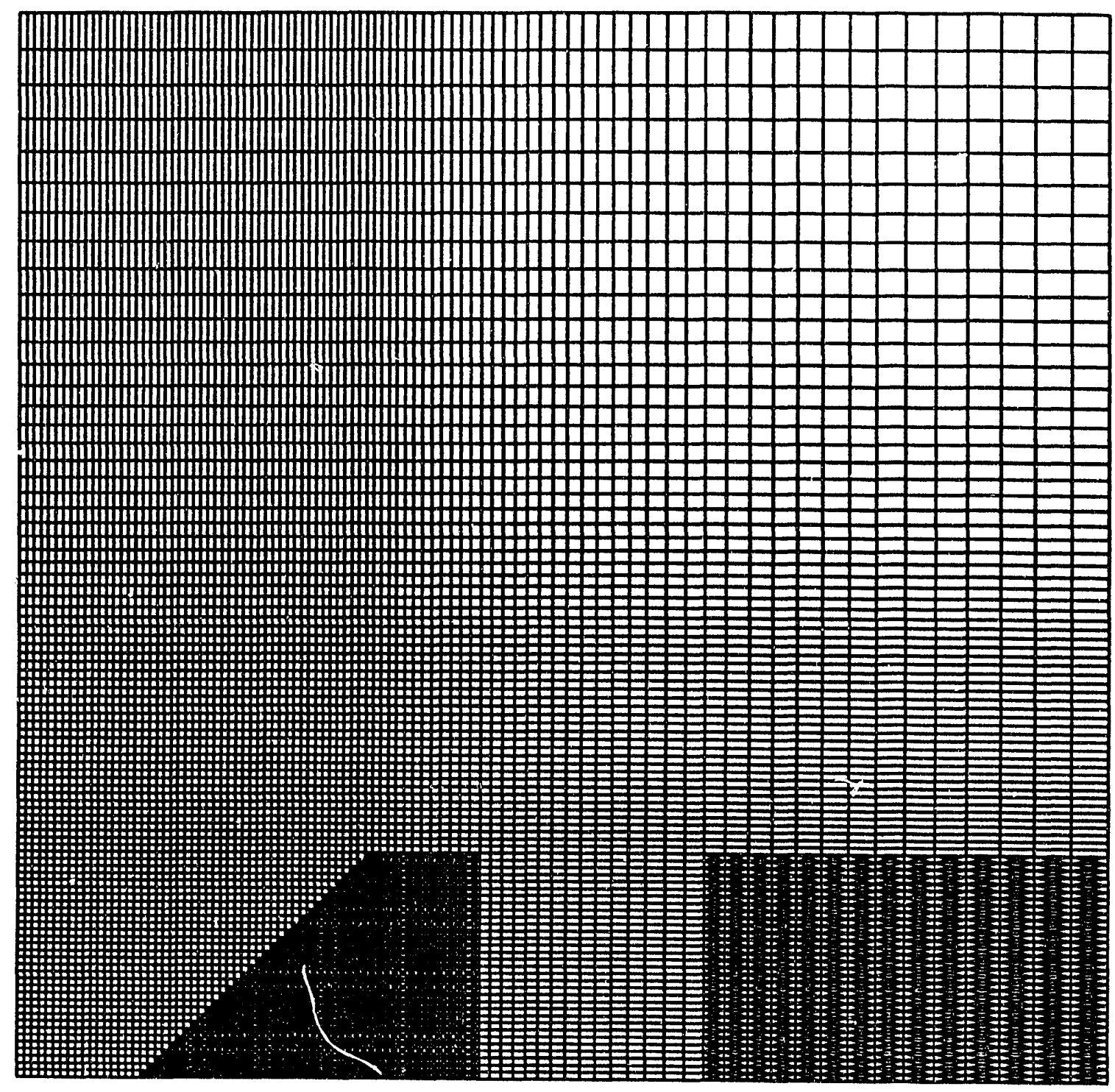

Fig. 2. Computational mesh used for the $12 \mathrm{~cm}$ by $12 \mathrm{~cm}$ calculations. The slot at the center of the obstacle is a channel for secondary air, which has a zero flow rate in the present calculations. 

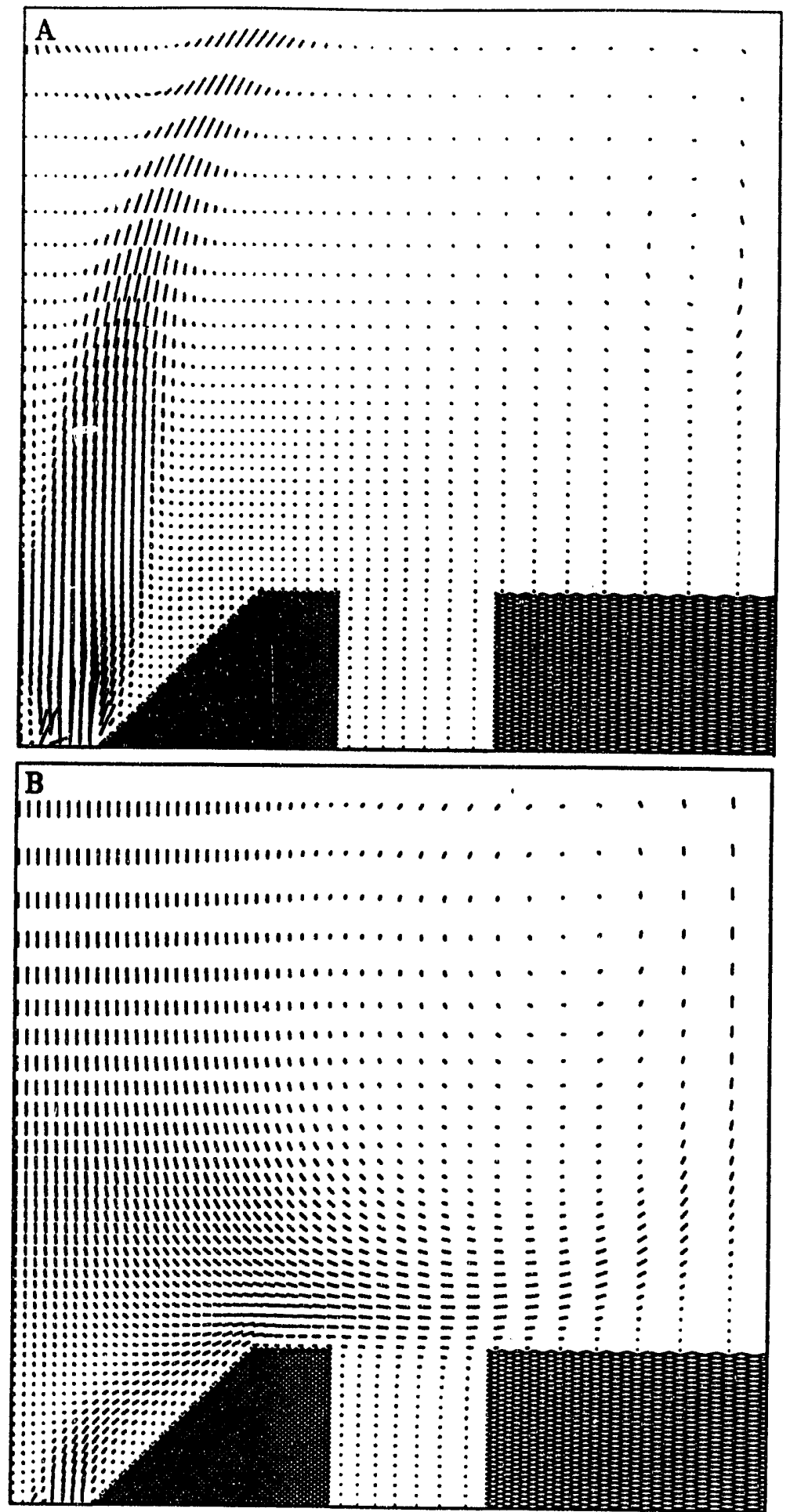

Fig. 3. Velocity vector plots for the nonreactive cases where inflow is prevented along the top boundary (A) and where inflow is allowed along the top boundary (B). Maximum fluid speeds are 2398 and $2964 \mathrm{~cm} / \mathrm{s}$, respectively. 

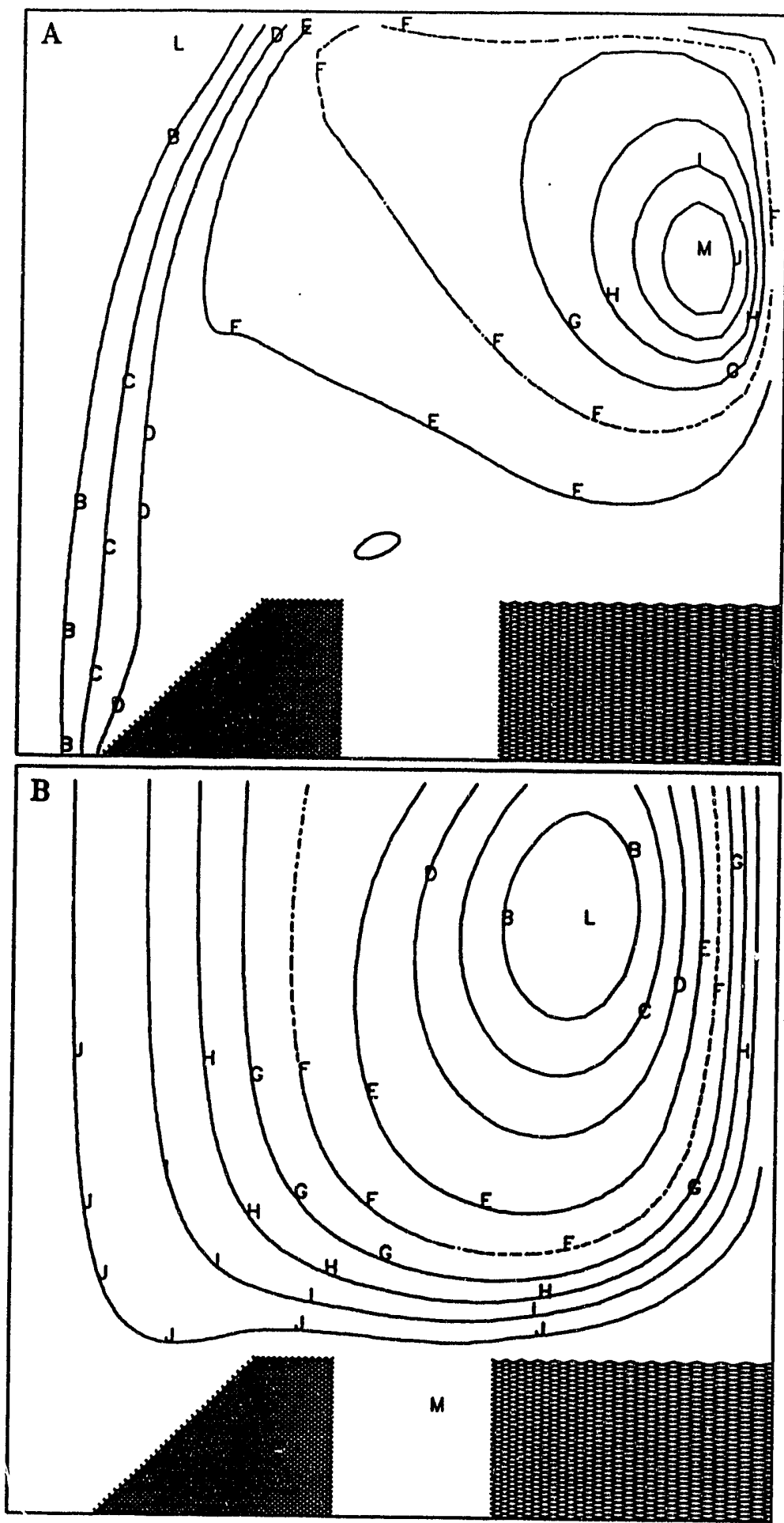

Fig. 4. Stream function plots for the non reactive cases where inflow is prevented along the top boundary $(A)$ and where inflow is allowed along the top boundary (B). The minimum values, maximum values, and contour intervals are $(-0.4872,6.3889,0.6876)$ and $(-46.9553,3.7284,5.0684)$, respectively. 


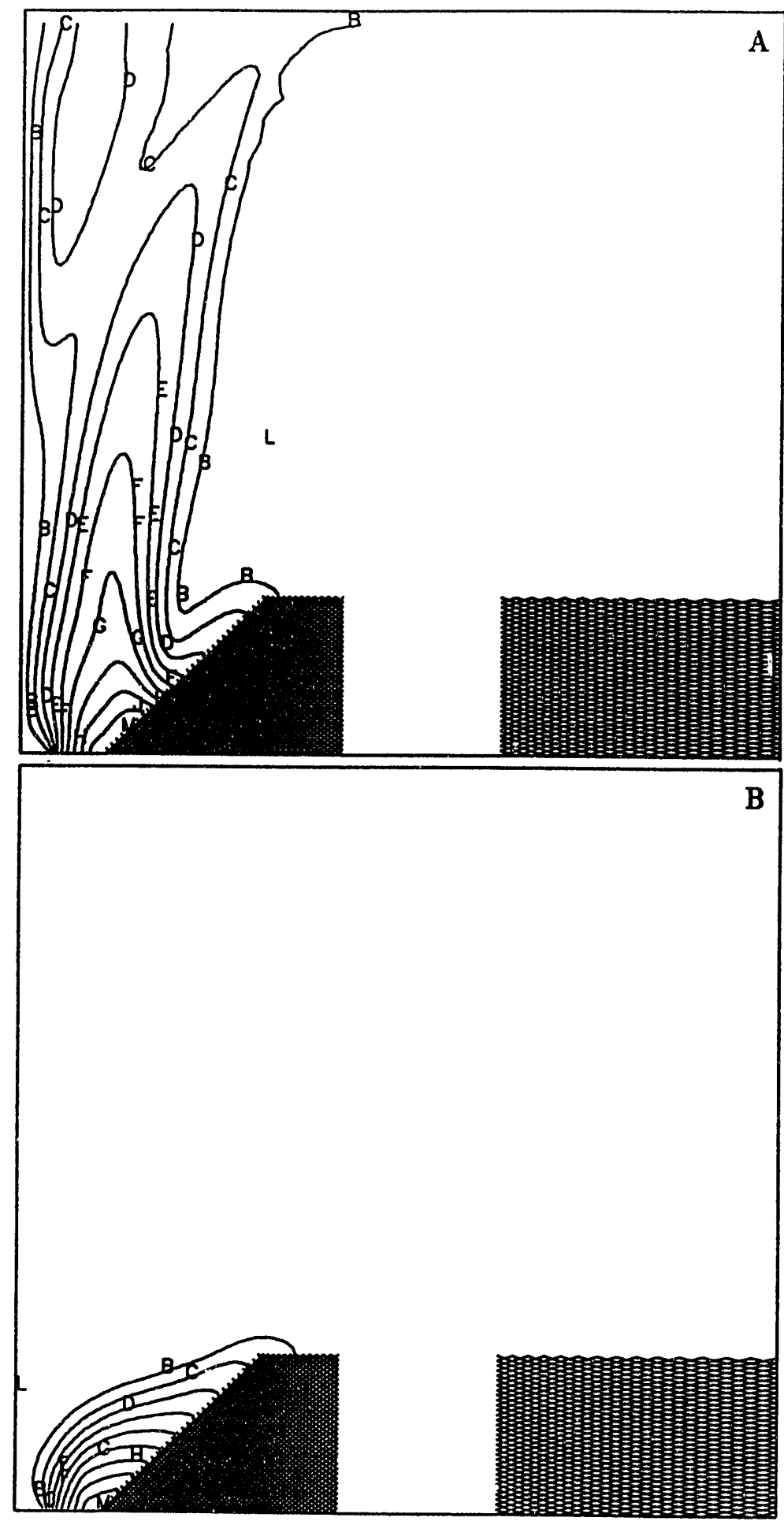

Fig. 5. Contours of swirl velocity for the noreactive cases where inflow is prevented along the top boundary (A) and where inflow is allowed along the top boundary (B). The minimum values, maximum values, and contour intervals are $(0,1109,111)$ and $(0,1085,108) \mathrm{cm} / \mathrm{s}$, respectively. 


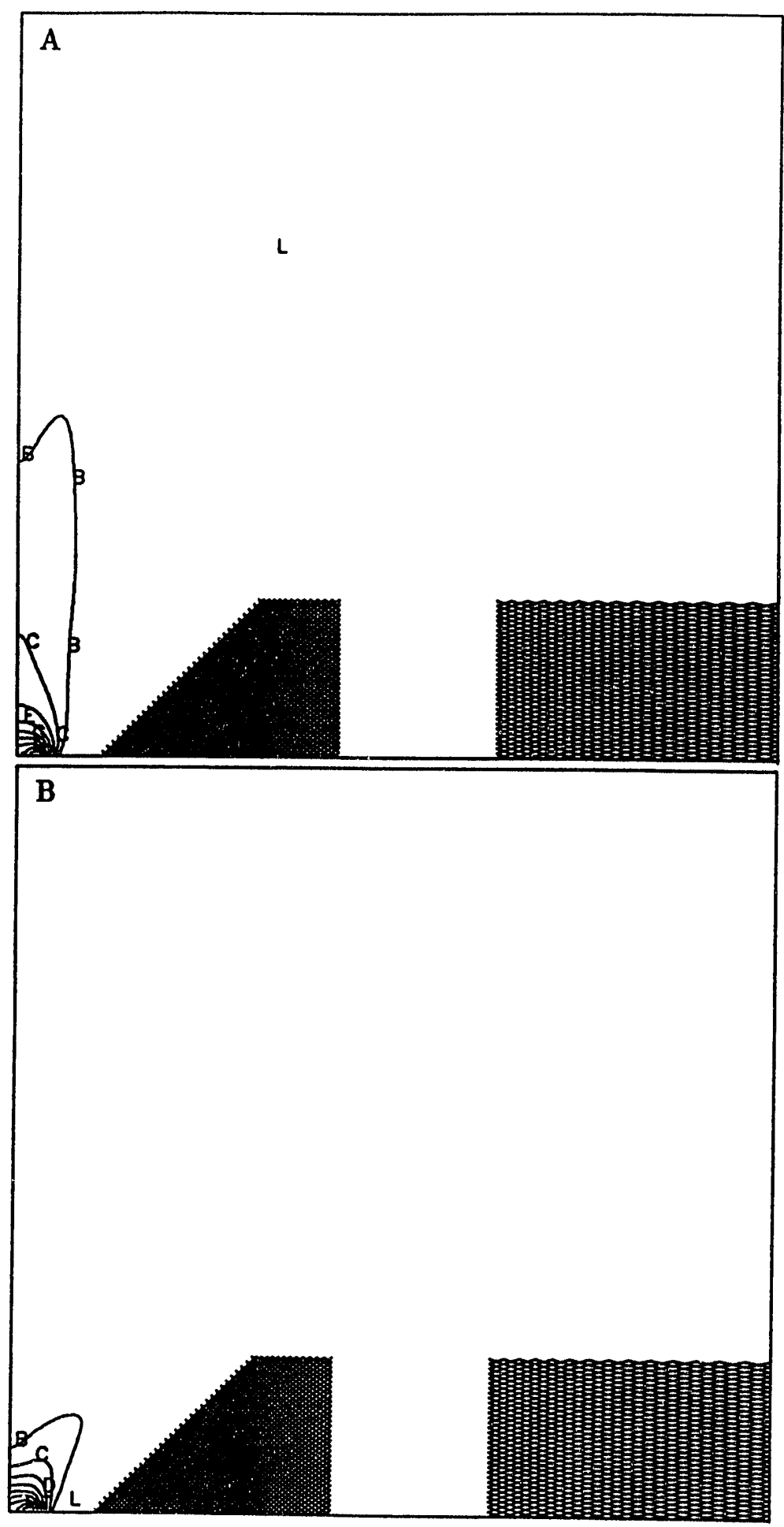

Fig. 6. Contours of methane mass fraction for the nonreactive cases where inflow is prevented along the top boundary (A) and where inflow is allowed along the top boundary (B). The minimum values, maximum values, and contour intervals are $(0.0,0.8683,0.0868)$ and $(0.0,0.8620$, 0.0862 ), respectively. 


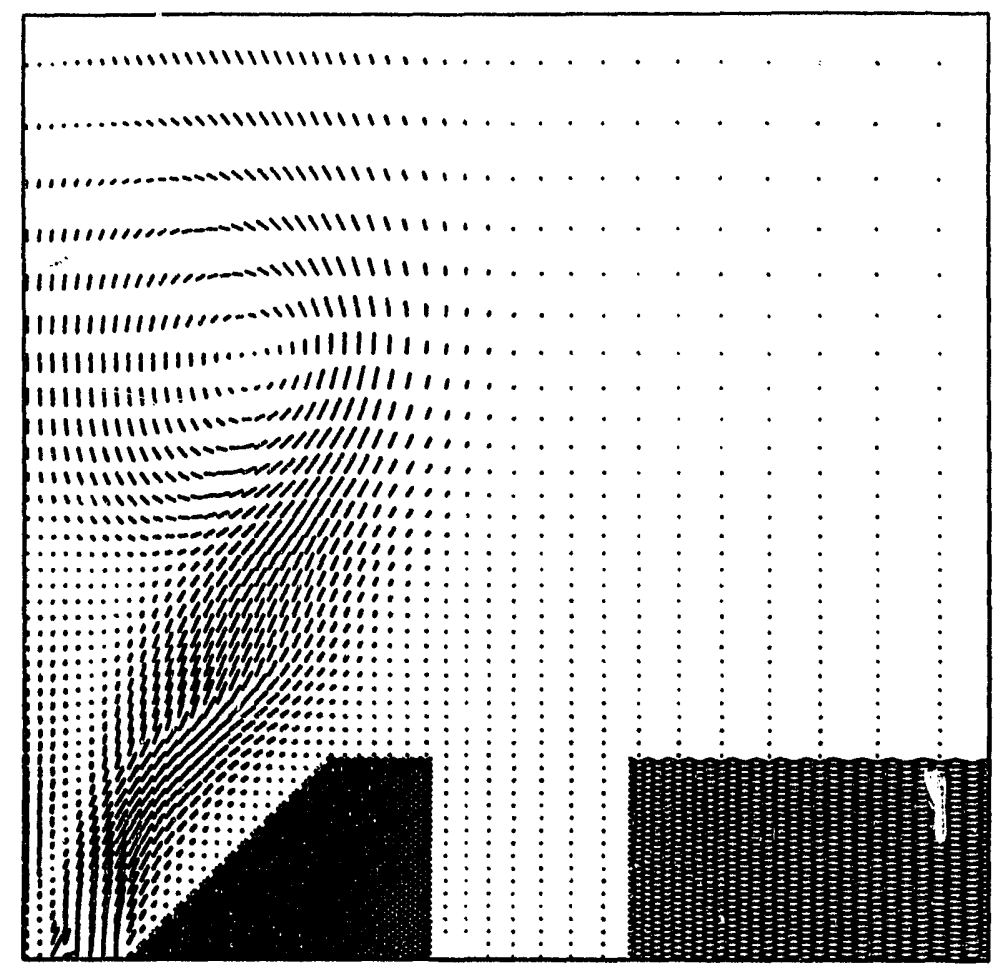

Fig. 7. Velocity vectors for the swirling reactive flow. Inflow is prevented along the top boundary. Maximum fluid speed is $2432 \mathrm{~cm} / \mathrm{s}$.

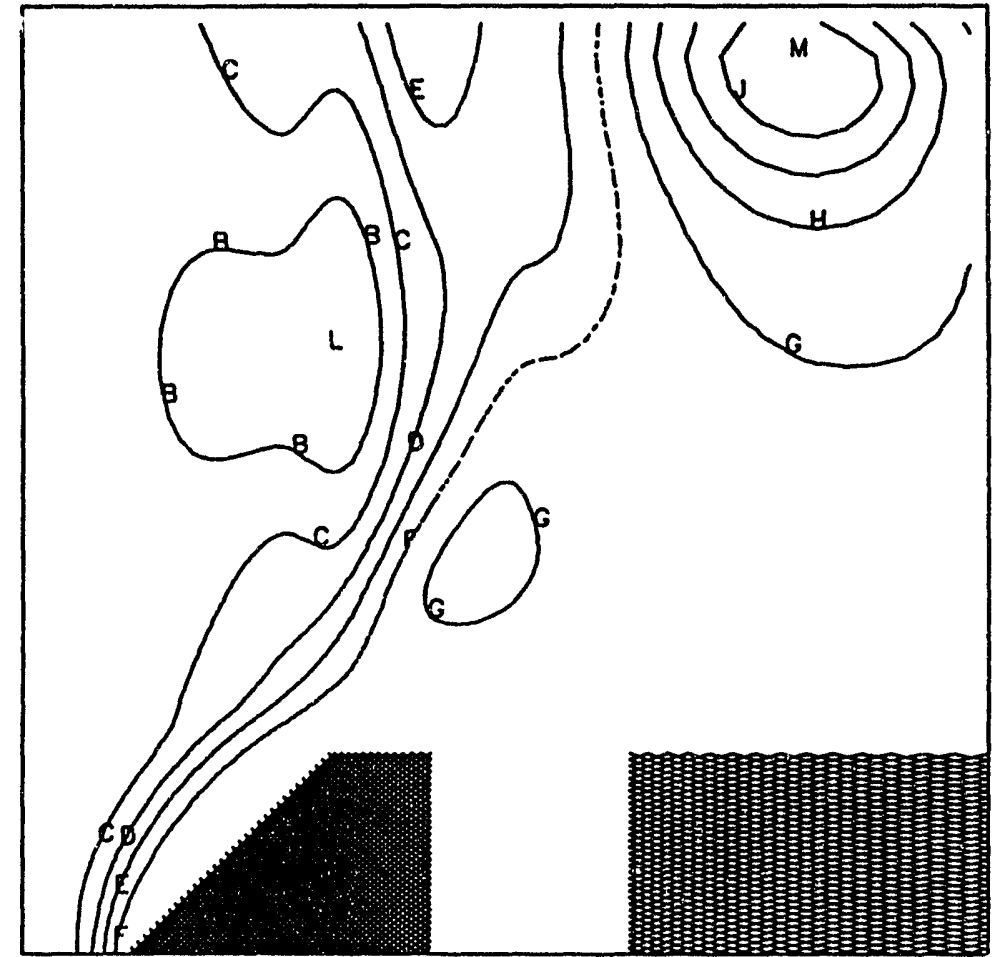

Fig. 8. Stream function contours for the swirling reactive flow. The minimum value, maximum value, and contour interval are $(-0.6361,3.2507,0.3887)$. 


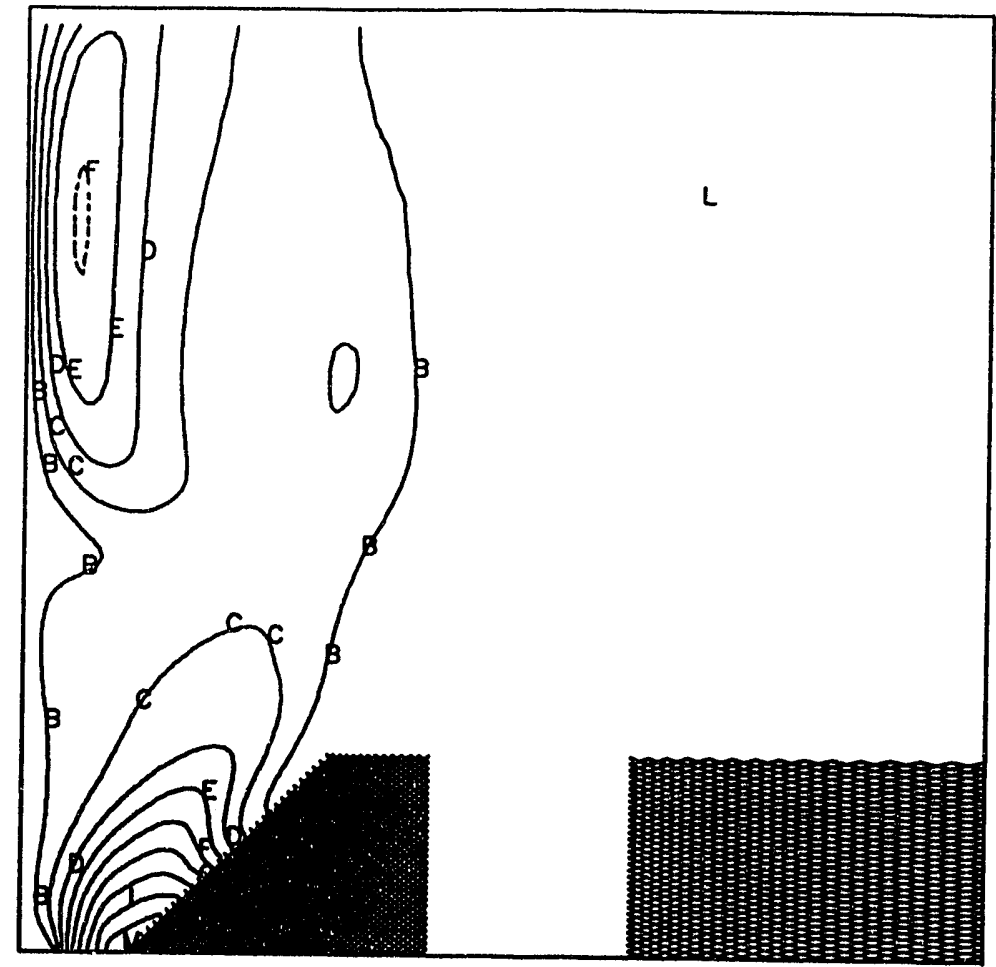

Fig. 9. Swirl velocity contours for the swirling reactive flow. The minimurn value, maximum value, and contour interval are $(0,1091,109) \mathrm{cm} / \mathrm{s}$.

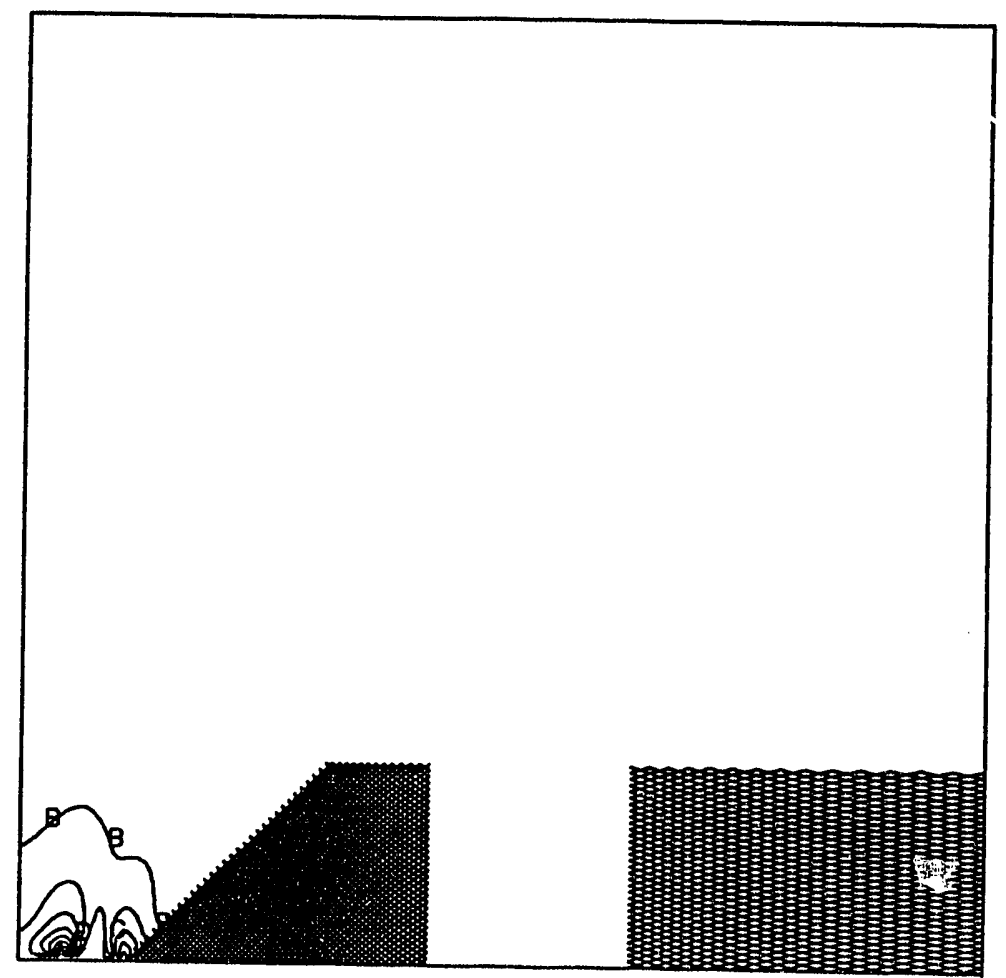

Fig. 10. Turbulence kinetic energy density contours for the sivirling reactive flow. The minimum value, maximum value, and contour interval are $\left(0.0,2.9499 \times 10^{6}, 2.9499 \times 10^{5}\right) \mathrm{cm}^{2} / \mathrm{s}^{2}$. 


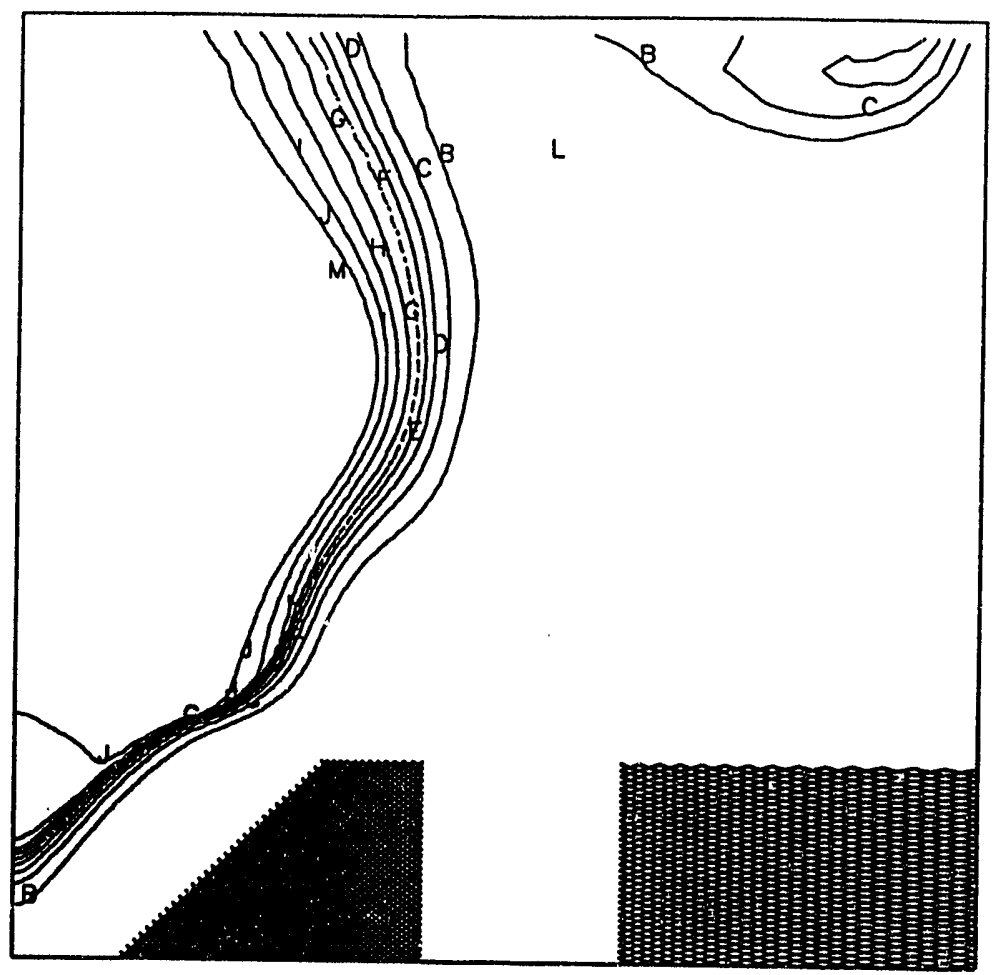

Fig. 11. Temperature contours for the swirling reactive flow. The minimum value, maximum value, and contour interval are $(296,2294,200) \mathrm{K}$.

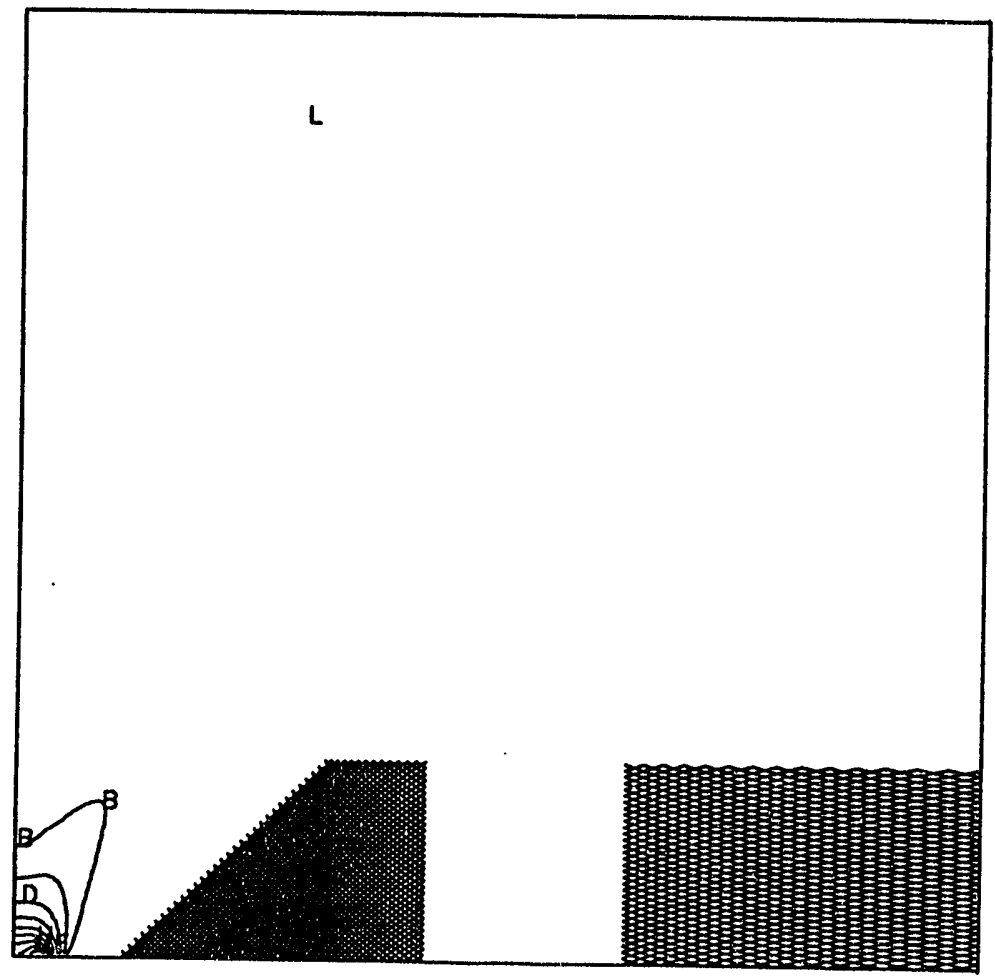

Fig. 12. Methane mass fraction contours for the swirling reactive flow. The minimum value, maximum value, and contour interval are $(0.0,0.8746,0.0875)$. 


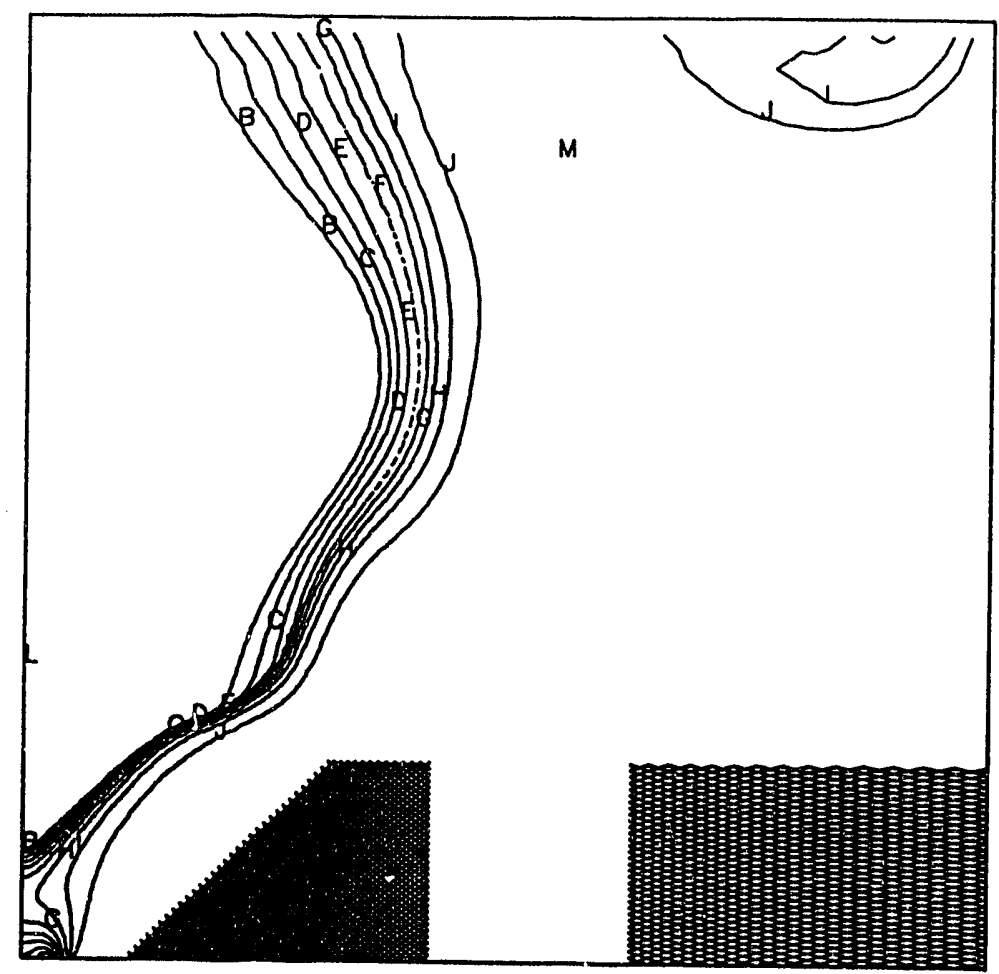

Fig. 13. $\mathrm{O}_{2}$ mass fraction contours for the swirling reactive flow. The minimum value, maximum value, and contour interval are $(0.00004,0.2319,0.0232)$.

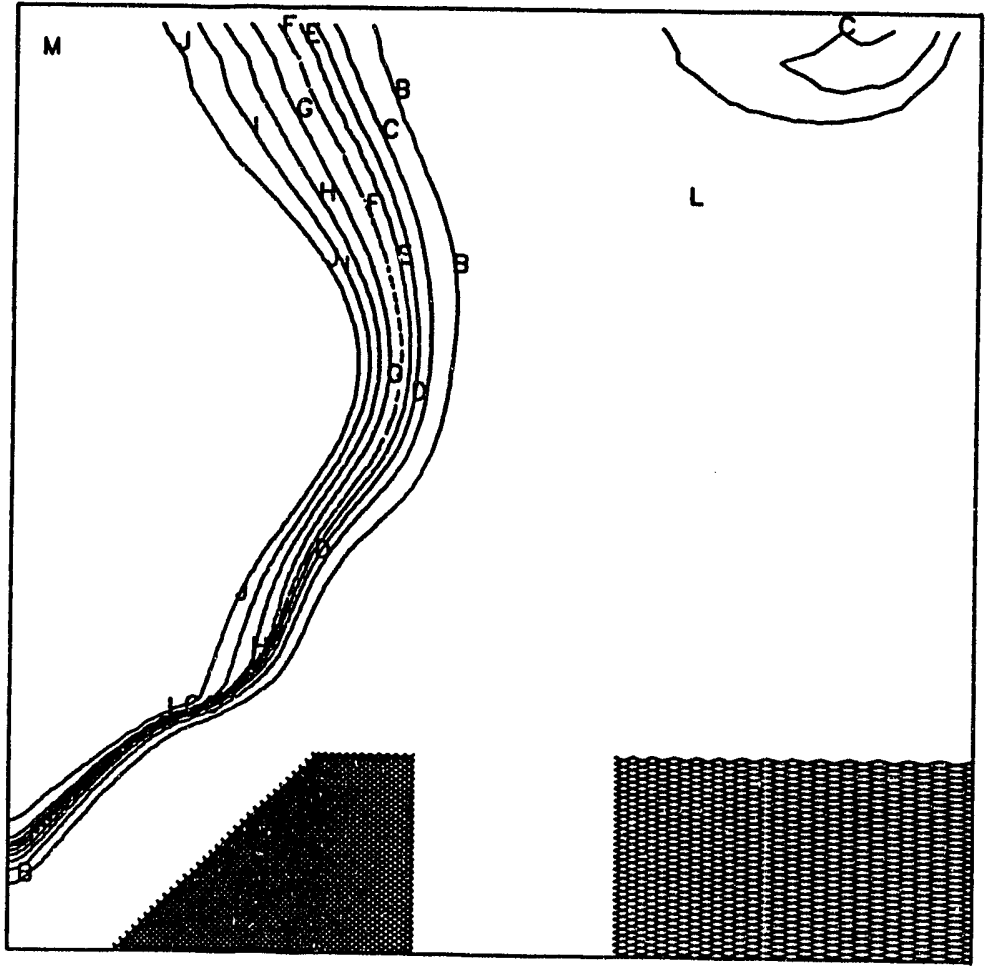

Fig. 14. Water mass fraction contours for the swirling reactive flow. The minimum value, maximum value, and contour interval are $(0.0,0.1281,0.0128)$. 


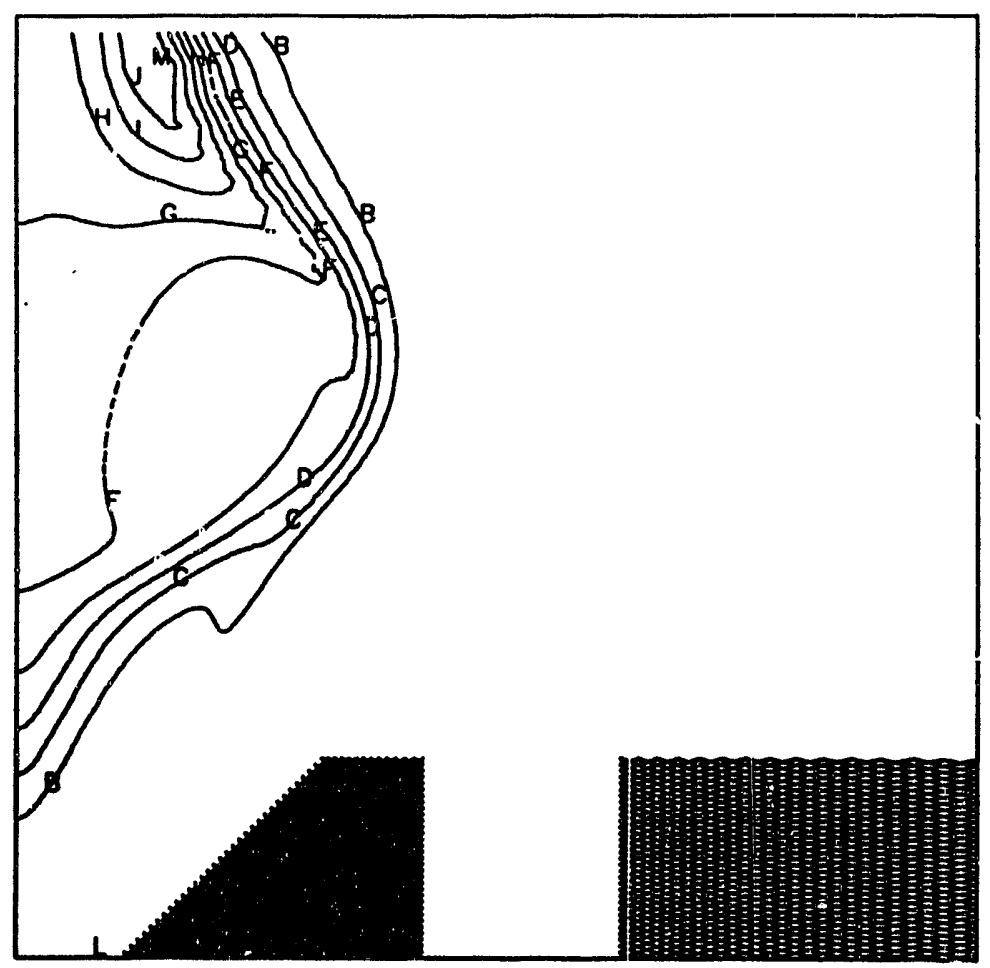

Fig. 15. Thermal NO mass fraction contours for the swirling reactive flow. The minimum value, maximum value, and contour interval are $\left(0.0,1.7187 \times 10^{-4}, 1.7187 \times 10^{-5}\right)$.

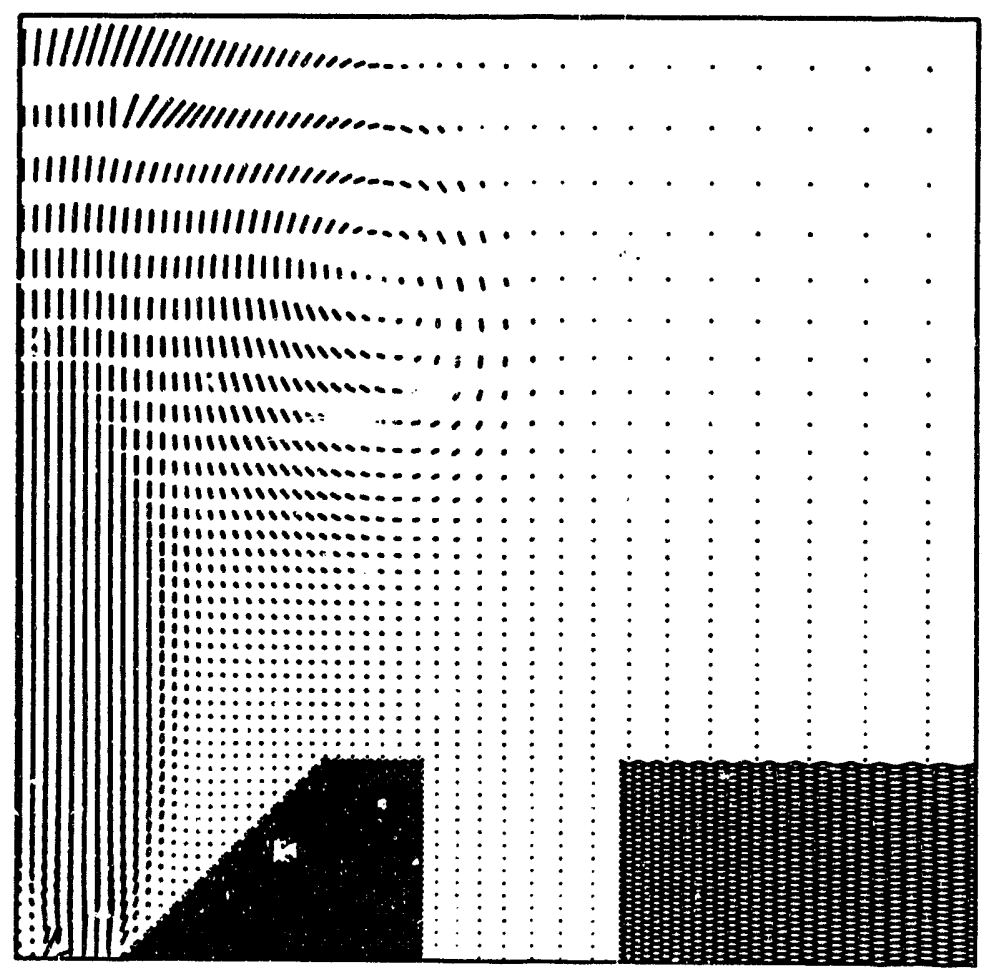

Fig. 16. Velocity vectors for the non-swirling reactive flow. Inflow is prevented along the top boundary. Maximurn fluid speed is $2419 \mathrm{~cm} / \mathrm{s}$. 


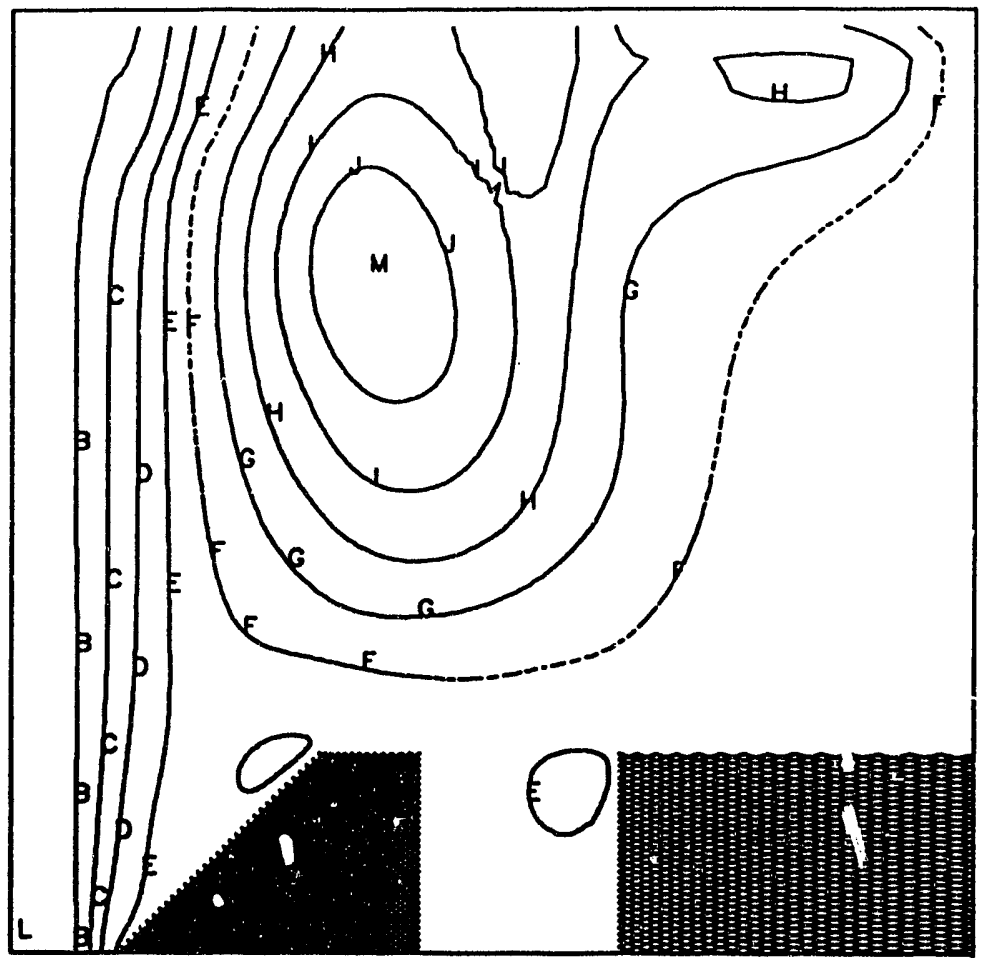

Fig. 17. Stream function contours for the non-swirling reactive fiow. The minimum value, maximum value, and contour interval are $(-0.0008,4.0534,0.4054)$.

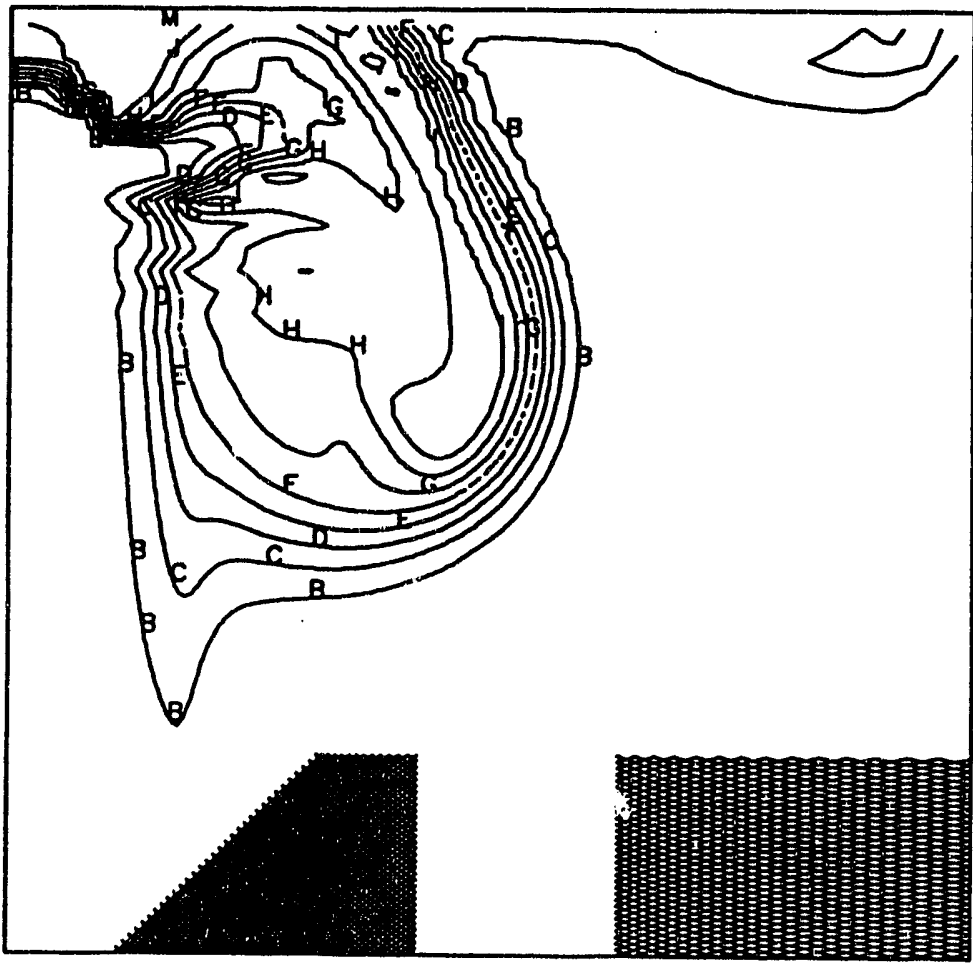

Fig. 18. Temperature contours for the non-swirling reactive flow. The minimum value, maximum value, and contour interval are $(253,2239,199) \mathrm{K}$. 


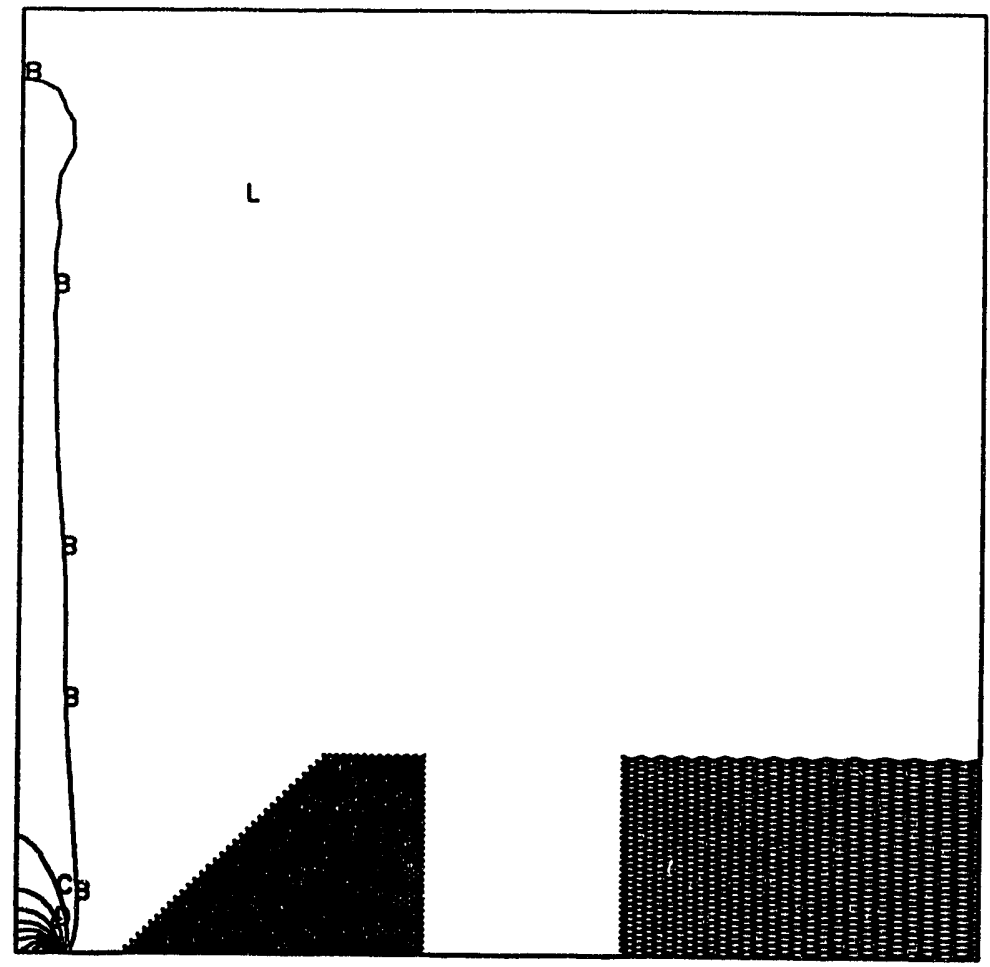

Fig. 19. Methane mass fraction contours for the non-swirling reactive flow. The minimum value, maximum value, and contour interval are $(0.0,0.8696,0.0870)$. 

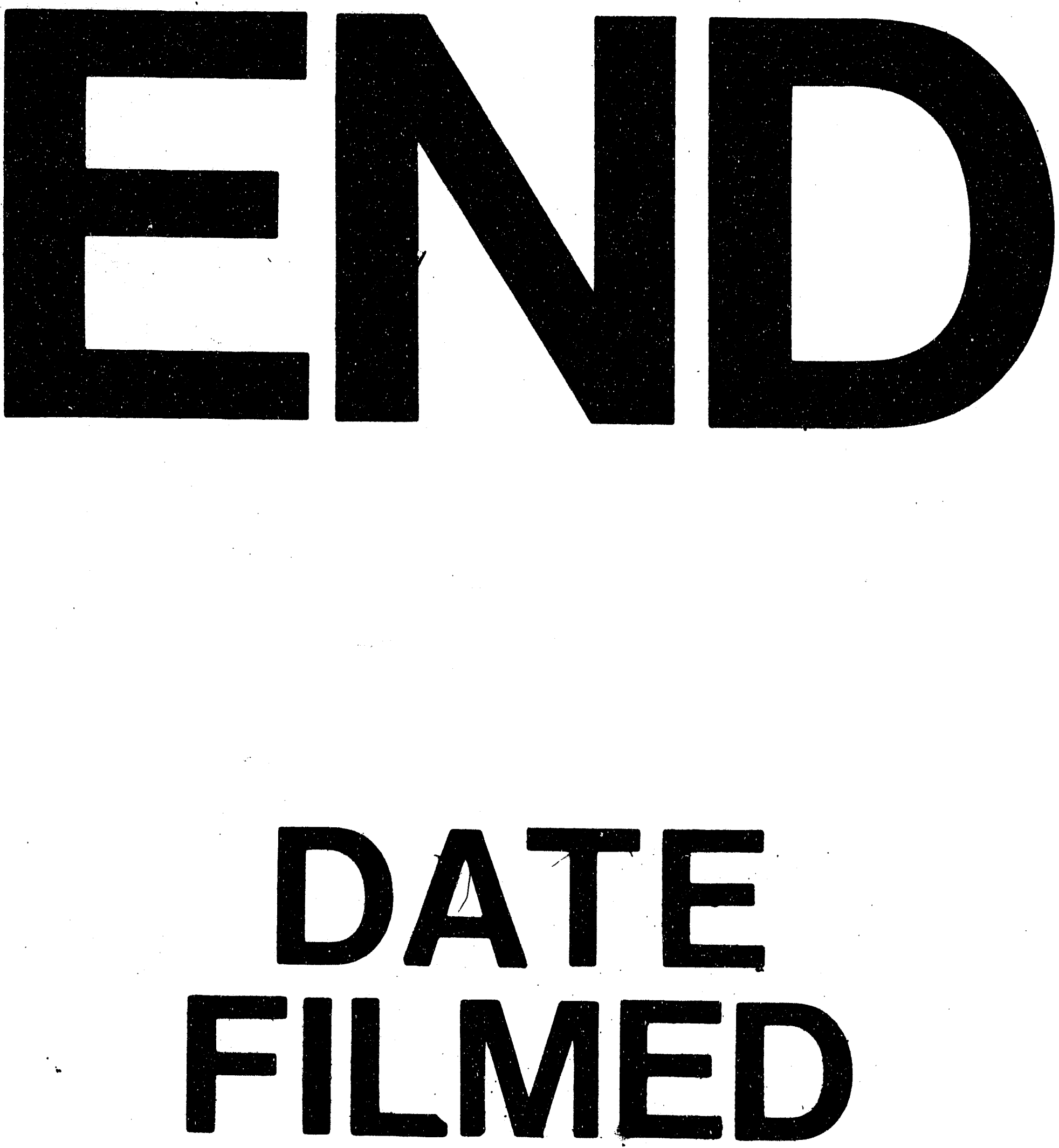

1

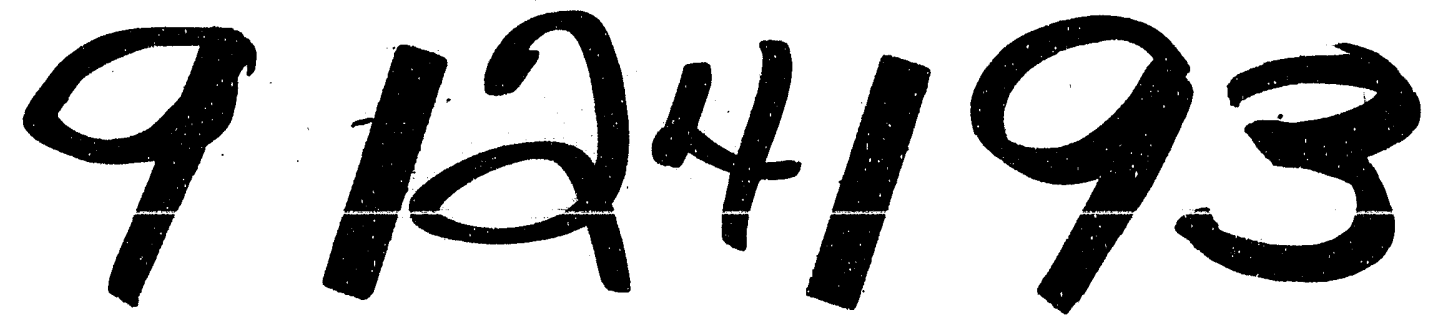


